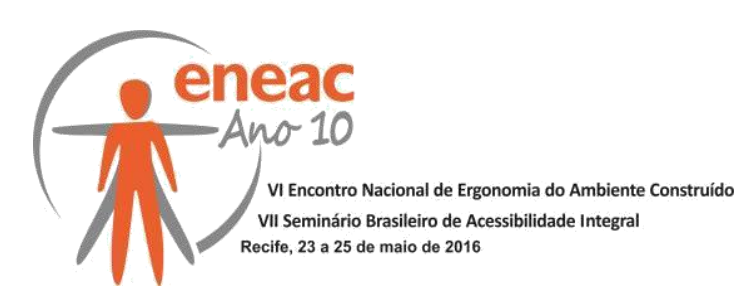

\title{
RESGATANDO A HABITABILIDADE LOCAL: INSERÇÃO DE ROTA ACESSÍVEL NO CENTRO HISTÓRICO DE JOÃO PESSSOA - PB
}

\author{
MEDEIROS, Haendel Lopes Virgulino de (1); \\ MATIAS, Emanoella Bella Sarmento S. E. (2); \\ COSTA, Angelina Dias Leão (3) \\ (1) UFPB, Graduando em Arquitetura e Urbanismo \\ e-mail: haendelopes@gmail.com
}

(2) UFPB, Mestra

e-mail: emanoellasarmento85@gmail.com

(3) UFPB, Doutora

e-mail: angelinadlcosta@yahoo.com.br

\begin{abstract}
RESUMO
O estudo propõe uma Rota Acessível Externa (RAE) considerando a integração entre lotes elencados para Habitação de Interesse Social e seu entorno imediato no Centro Histórico de João Pessoa/PB a fim de contribuir para a reinserção da habitabilidade do local. A metodologia baseou-se no levantamento físico da área para mapeamento das condições de mobilidade; identificação dos pontos de inacessibilidade e reflexão acerca de possíveis melhorias. As condições encontradas permitiram uma RAE conectada a serviços, transporte e aos respectivos lotes destinados à habitação. A possibilidade de inserir acessibilidade na área tornou evidente a possibilidade de valorização do usuário ali instalado.
\end{abstract}

Palavras chave: Rota Acessível Externa. Habitação de Interesse Social. Acessibilidade. Habitabilidade.

\begin{abstract}
The study proposes a Route External Accessible (SAR) considering the integration between batches listed for Social Housing and its immediate surroundings in John's Historical Center Pessoa / PB to contribute to rehabilitate the housing site. The methodology was based on the physical survey of the area to map the conditions for mobility ; identification of inaccessibility points and think about possible improvements. The conditions found allowed a SAN connected to the services, transport and their lots for housing. The possibility of inserting accessibility in the area made the possibility of recovery of the user installed there ..
\end{abstract}

Keywords: External Affordable route. Social Housing. Accessibility. Habitability. 


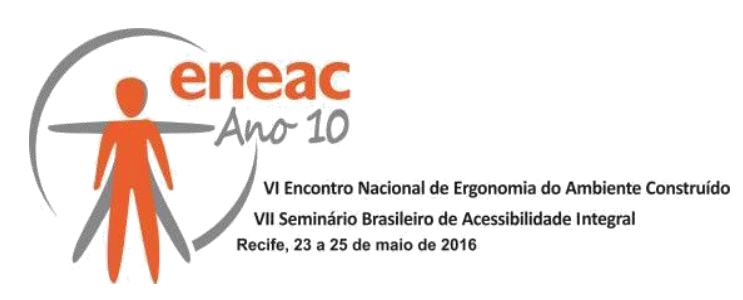

\section{INTRODUÇÃO}

Garantir o acesso a todos é permitir que a população usufrua da cidade de maneira homogênea. Para tanto, o espaço urbano deve ser integrado, com ampla circulação do transporte coletivo para que o deslocamento dos passageiros seja fluido e seguro, com calçadas que se adequem aos princípios do desenho universal e, possibilitando às pessoas com limitações físico-motoras, a livre circulação pela cidade.

A cidade, enquanto cenário de socialização tem papel fundamental na construção das relações diárias, seja entre seus usuários ou na relação com os seus ambientes. A presença de obstáculos nos espaços públicos e privados exclui o homem como sujeito atuante deste meio e, o que antes seria cenário para troca de experiências, acaba por agir como um meio segregador e excludente das interações urbanas.

Nos sítios históricos essa realidade acaba sendo mais dura, pois em meio a espaços grandiosos e ricos em detalhes arquitetônicos, a possibilidade de adaptação parece, num primeiro instante, diminuir as possibilidades de torná-los acessíveis e capazes de proporcionar ao pedestre (pessoas com e sem deficiência e ainda aquelas com mobilidade reduzida) condições de uso adequadas. Logo, a relação inicial entre o ambiente e seu usuário é barrada pela falta de acesso e, a percepção, consequência de estímulos provocados por tal ambiente sobre os sentidos dos usuários, é impedida (REIS \& LAY, 2010, p.106).

Para tanto, a reflexão e associação da Habitação de Interesse Social (HIS) nessas áreas tem se tornado uma alternativa positiva quanto à transformação e melhoria da dinâmica urbana desses locais. Segundo (LARCHER, 2006 p.6) embora o interesse social da habitação se manifeste principalmente em relação ao aspecto de inclusão das populações de baixa renda, pode também manifestar-se em relação a outros ângulos, sejam eles, situações de risco, preservação ambiental ou cultural.

Dessa maneira surge nesses locais uma série de mudanças necessárias à transformação e à implantação da habitabilidade. Para Tuan (1983), "espaços" transformam-se em "lugares" quando permitem que o indivíduo desenvolva afetividade (positiva ou negativa) em relação a este local e isso só é possível através da experiência urbana. Nesse sentido, espaços inacessíveis para pessoas com deficiência ou com mobilidade reduzida dificultam os processos de afeto e construção do lugar, impedindo muito mais do que o acesso, já que interferem na sua construção identitária e na sua relação com o outro (DUARTE e COHEN, 2010).

A questão da moradia requer fatores indispensáveis para que o ser humano possa desempenhar suas atividades, como: acessibilidade e mobilidade, educação, segurança e transporte. Quando associada a esses fatores facilita a integração social, possibilitando o retorno da dinâmica urbana daqueles espaços. Conforme Carvalho (2012), esse processo é responsável por trazer moradores que irão ocupar o espaço durante o dia e a noite. Desta forma, se faz necessário pensar o habitacional não de forma isolada e sim como um processo conectado e sustentável, onde se pense o social, habitacional, econômico e ambiental.

A Rota Acessível Externa (RAE) proposta nesse estudo busca contribuir para a habitabilidade local em dois lotes destinados à HIS no Centro Histórico de João Pessoa PB. Para isso, recorreu à avaliação da área e do seu entorno imediato, objetivando a conexão de serviços e outros pontos significativos.

Revestido de grande importância para a memória e identidade da cidade, o Centro Histórico $(\mathrm{CH})$ de João Pessoa (Figura 1) tem uma delimitação física abrangente, com expressivo número de monumentos e bens imóveis de interesse histórico e cultural. É o núcleo onde se 


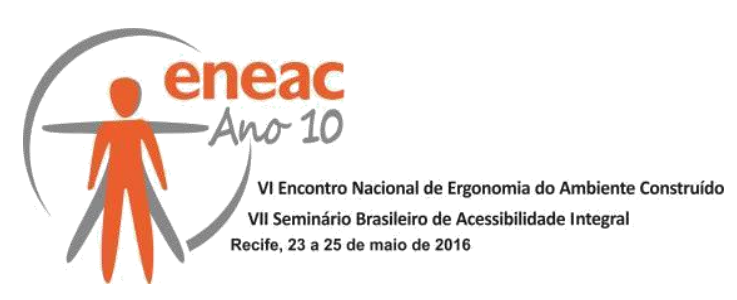

originou a cidade e que evoluiu acompanhando as mudanças políticas, econômicas e sociais (CASTRO, 2006).

\section{FIGURA 1 - Poligonal de tombamento estadual (Área de Preservação do Entorno) e Área de Preservação Rigorosa (tombamento nacional) do Centro Histórico de João Pessoa.}

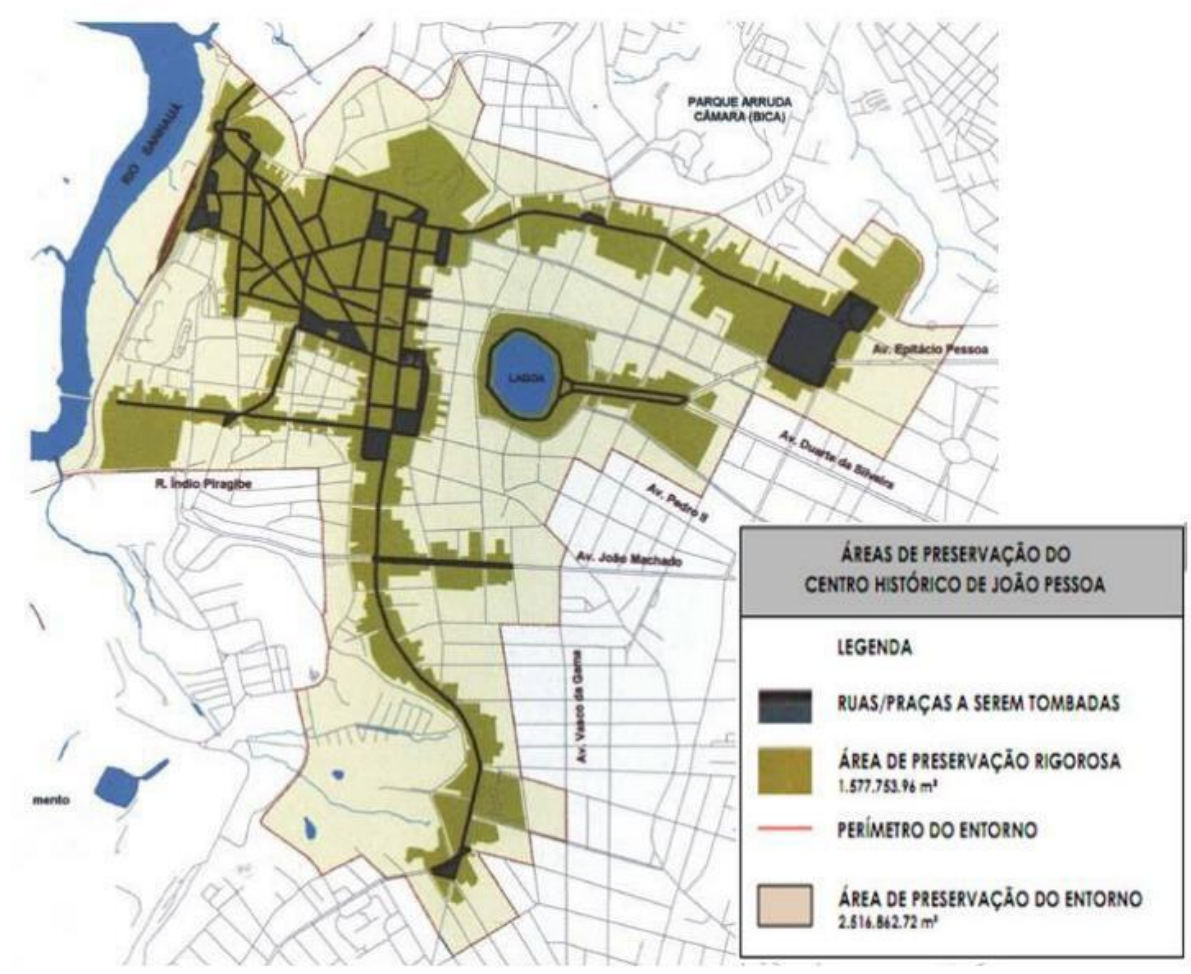

Fonte: Decreto nº 25.138 (GOVERNO DO ESTADO DA PARAÍBA, 2004).

De acordo com Del Rio (1993, p.54), a importância das áreas centrais está profundamente ligada às lógicas histórica e sócio espacial, e é por isto que elas se destacam na percepção e vivência de qualquer cidade. Repletos de simbolismos, história, valores e, sobretudo, da identidade daqueles que dele fazem parte, o núcleo central das cidades deve funcionar como dinamizador da sociedade, com suas diferentes funções e características. Porém, algumas áreas, devido às suas especificidades topográficas e evolução do crescimento têm sofrido com a desvalorização e abandono, tornando-se com frequência, áreas vazias e esquecidas.

Sob condições de marginalização e esquecimento, o Centro Histórico de João Pessoa não está distante da realidade das cidades, e reúne, ainda, outras limitações, onde impedimentos ambientais e barreiras arquitetônicas são recorrentes. Derivado de épocas em que a acessibilidade não era premissa de projeto, estes espaços acabaram por se tornar de difícil acesso, com desníveis e barreiras acentuadas.

Para tanto, este artigo tem como objetivo propor um trecho de RAE no Centro Histórico de João Pessoa - PB, de maneira a tornar habitável dois lotes destinados à HIS. A partir da integração e conexão de seu entorno imediato baseados no acesso seguro e autônomo.

Diante da importância da inserção da acessibilidade em uma porção do Centro Histórico de João Pessoa, este estudo se justifica pela necessidade do resgate social e cultural da área, uma vez que, a acessibilidade poderá favorecer o retorno da dinâmica urbana local, da 


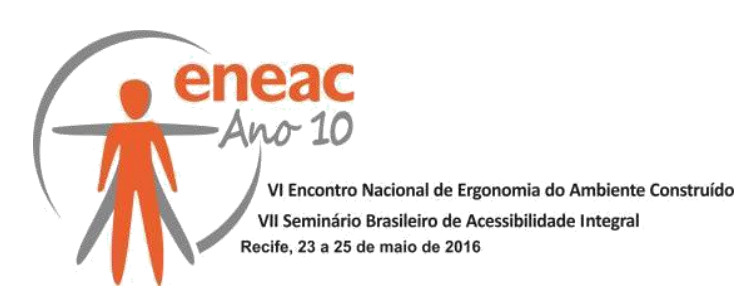

habitabilidade e inclusão, a partir do acesso facilitado e indiscriminado a todas as pessoas (com e sem deficiência) àquele trecho do patrimônio da cidade.

\section{MÉTODOS E TÉCNICAS}

Realizou-se uma pesquisa teórica e conceitual sobre acessibilidade, HIS e legislações vigentes que ofereceu suporte técnico e teórico para o desenvolvimento das atividades seguintes.

A aplicação do método walkthrough trouxe a primeira impressão da porção do $\mathrm{CH}$ a ser avaliado, bem como o reconhecimento prévio dos pontos mais críticos e trechos com maior potencial de inserção de acessibilidade. Para isso, foi realizado um passeio por todas as calçadas existentes na porção delimitada desse $\mathrm{CH}$ (Figura 2), com o registro de fotografias e levantamentos físicos, além da percepção e apreensão de cada pesquisador quanto à realidade do local.

Figura 2 - Porção Delimitada do Centro Histórico onde ocorreu o estudo.

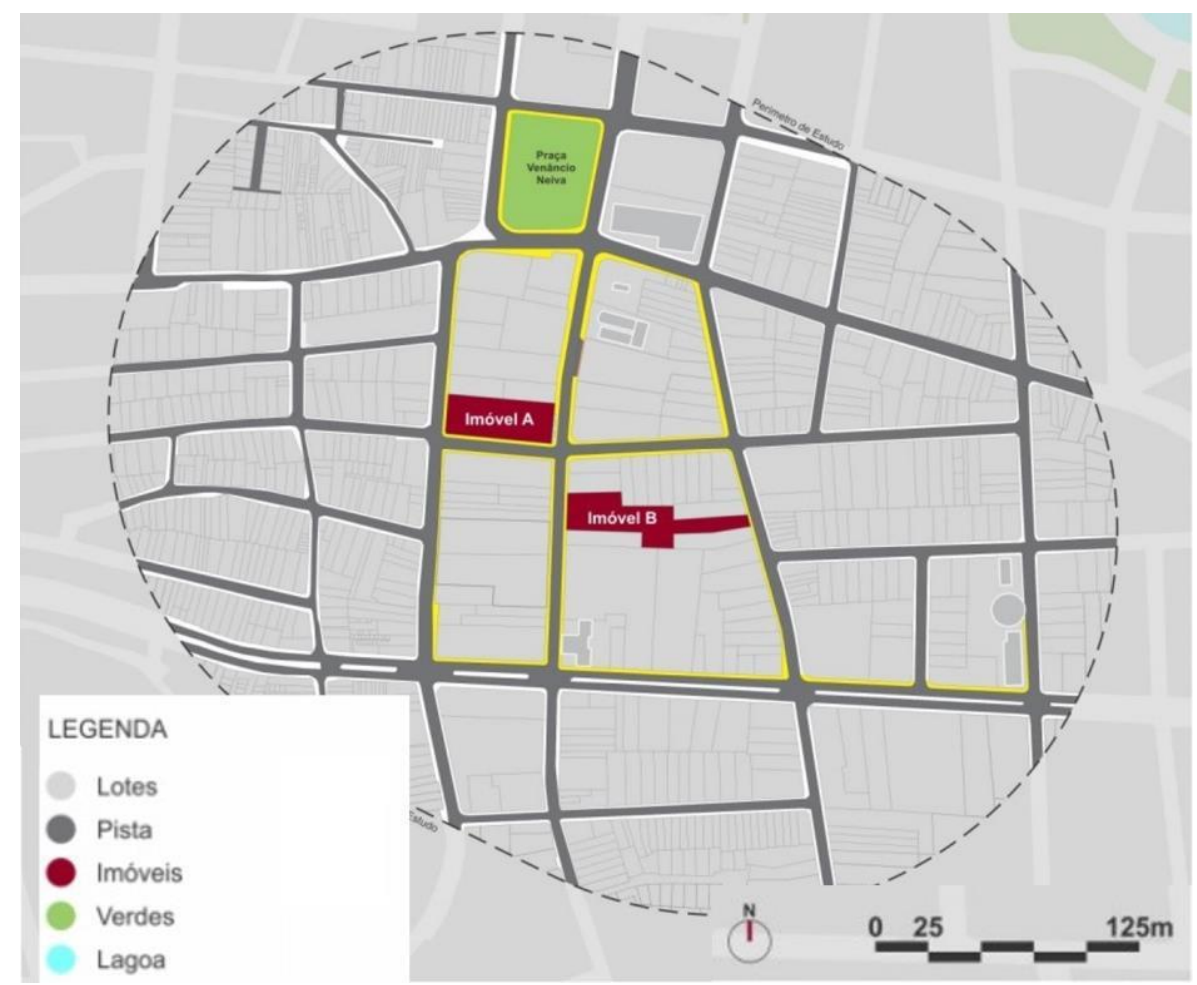

Fonte: Pesquisa de Campo

Após esse momento, pôde-se ter uma real dimensão do espaço, partindo então para o levantamento detalhado da área. Foram analisadas as condições ali existentes, verificando as atividades desenvolvidas no local e observando critérios de segurança, autonomia e mobilidade, sempre a partir do usuário e de forma ampla, incluindo as necessidades de crianças, idoso, gestantes, pessoas com mobilidade reduzida, entre outros. (ENGLES, 2002)

Logo, buscou-se construir um método que contemplasse informações tanto sobre o problema da situação existente quanto acerca das orientações fornecidas pelo documento de acessibilidade (NBR 9050/2015), objetivando auxiliar a obtenção do diagnóstico de acessibilidade deste trecho. 


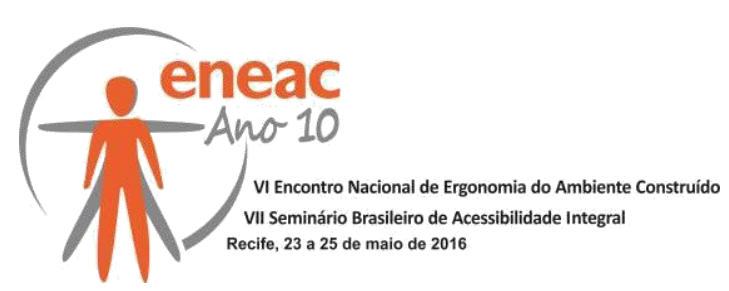

Para tanto, desenvolveu-se uma tabela contendo quatro segmentos (Figura 3). O primeiro destinou-se à ilustração do problema encontrado. A seleção destas imagens foi realizada após o levantamento fotográfico da área estudada, sendo esta etapa primordial para o início da percepção das barreiras arquitetônicas do ambiente urbano analisado. Após sua identificação, o problema foi descrito, tomando como parâmetro as recomendações da NBR 9050/2015 (ABNT, 2015), bem como as instruções sobre construções de calçadas contidas na cartilha "Conheça as regras para arrumar a sua calçada" (SÃO PAULO, 2012), passando a preencher, então, o segundo segmento da tabela.

Como principal parâmetro utilizado para a análise das calçadas, utilizou-se a largura, uma vez que determina se há espaço suficiente para adaptações, e quais necessidades elas podem atender. Classificadas segundo três faixas de tamanho foram, então, definidas a partir das indicações da NBR 9050/2015 (ABNT, 2015), na qual o tamanho mínimo aceitável é de $1,20 \mathrm{~m}$.

No terceiro segmento foram interpretadas as recomendações da NBR 9050/2015 (ABNT, 2015) adequando-as para a situação do problema exposto. E, por último, foi elaborada uma proposta de solução baseada na interpretação da norma. A ilustração foi desenvolvida a partir de uma intervenção sobre a imagem do problema, porém, com a inserção da alternativa encontrada.

Figura 3 - Tabela utilizada para indicação dos trechos de inacessibilidade.

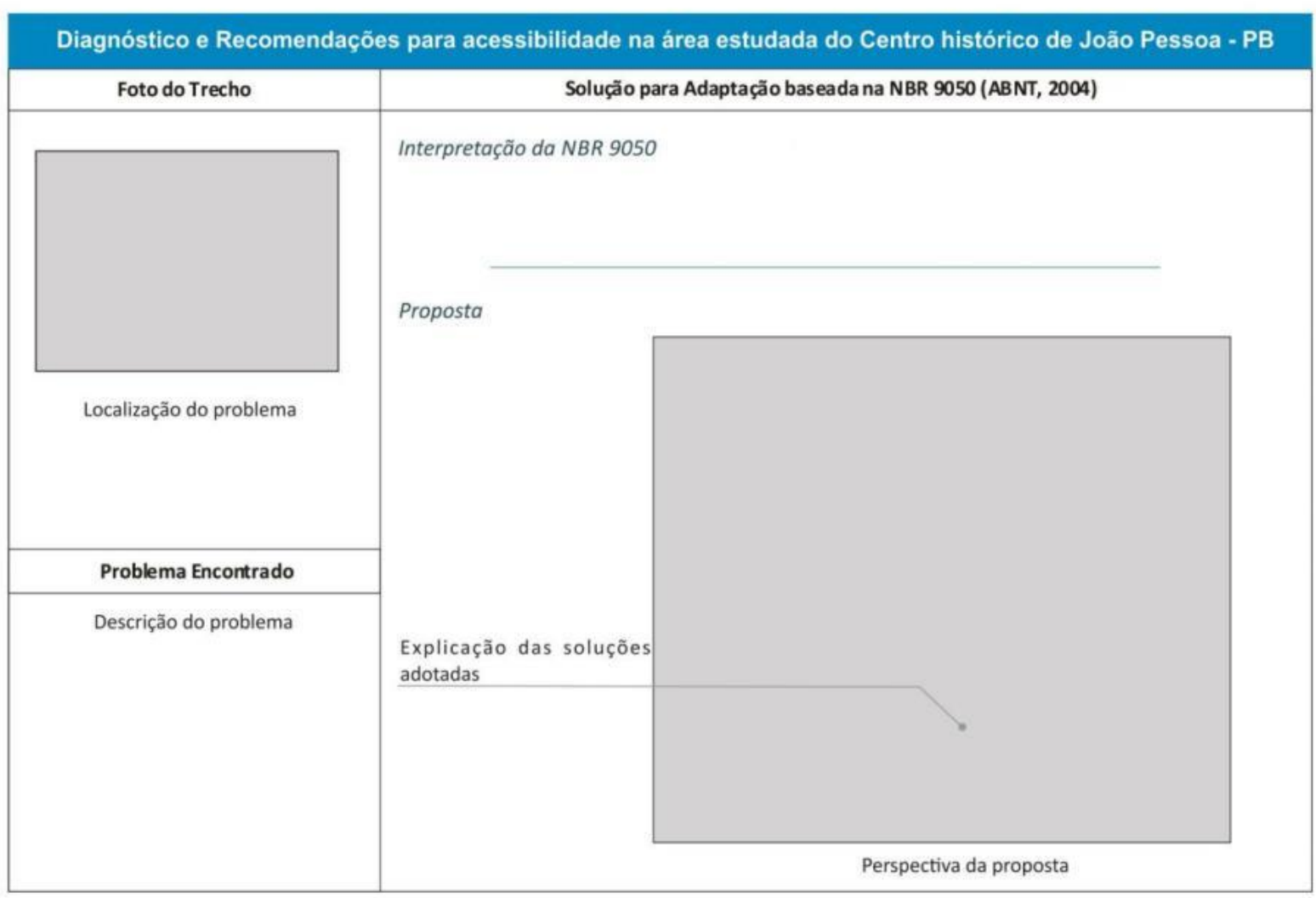

Fonte: Pesquisa de Campo 


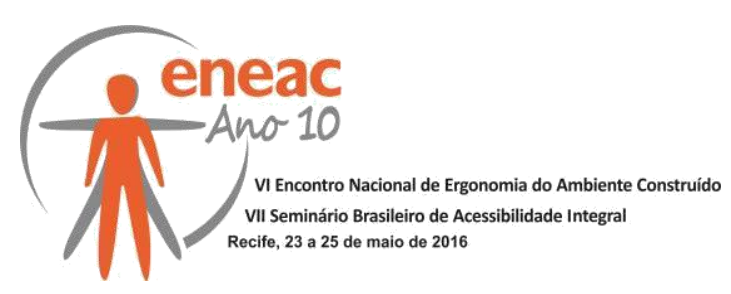

\section{CARACTERIZAÇÃO E DIAGNÓSTICO DA ÁREA}

Como em outros centros históricos brasileiros, o de João Pessoa apresenta, muitas vezes, as calçadas com dimensões estreitas para circulação de pedestres, problemas estruturais e de conservação (buracos e desníveis), bem como mobiliários urbanos que, por vezes, impedem ou dificultam o livre passeio.

O acesso irrestrito e universal aos locais públicos é fundamental a qualquer cidadão, estando contido no direito de ir e vir da Constituição Federal de 1988 (BRASIL, 1988). Assim, a garantia da acessibilidade do passeio das cidades torna-se um recurso forte na preservação da cidadania e dignidade de usuários, justificando a análise detalhada e sensível deste componente fundamental da via pública.

$\mathrm{Na}$ área de estudo foram encontrados diversos trechos de calçadas menores que este tamanho, dificultando uma intervenção nos mesmos. Ao mesmo tempo, também haviam muitas calçadas com dimensões apropriadas, ou seja, maiores que 1,20m (Figura 4). Sendo assim, essas informações foram decisivas na escolha do itinerário da rota.

Figura 4 - Mapa de identificação das calçadas com largura superior a 1,20 m.

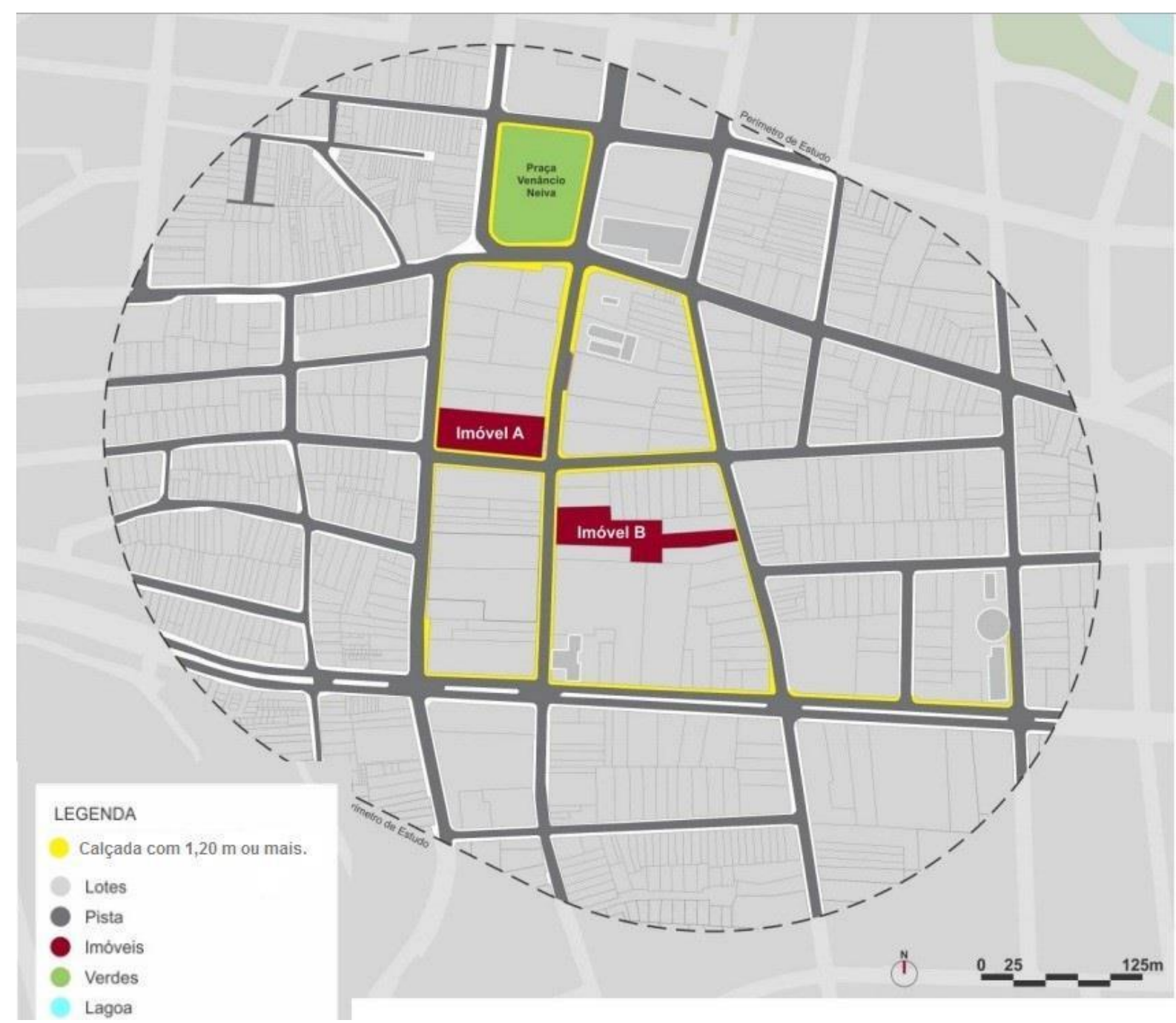

Fonte: Pesquisa de Campo 


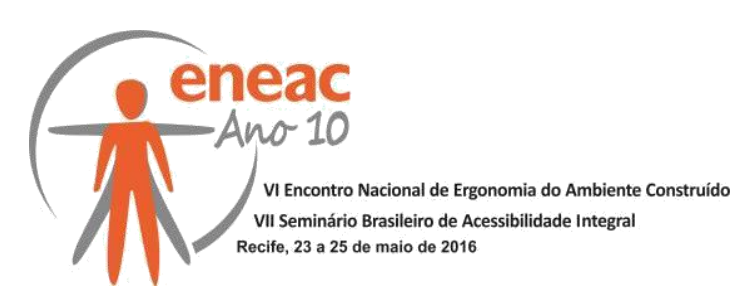

Constatou-se que aproximadamente a totalidade do passeio, cerca de $99 \%$, é passível de adaptação, já que possuem as dimensões mínimas de largura, enquanto os obstáculos encontrados são, em maioria, superáveis com intervenções primárias. Algumas medidas, no entanto, são dificultadas pelas variadas tipologias arquitetônicas existentes nesse sítio histórico, que sugerem soluções específicas a cada edificação no que se refere a sua adaptação de acordo com a inclinação da rota.

\section{$4 \quad$ A proposta da Rota Acessível}

A proposta desenvolvida, de modo geral, busca associar as HIS a elementos chave (Figura 5) que, agreguem valor e dinâmica à área estudada. Logo, foram elencados abaixo os principais conceitos relacionados à habitação.

\section{Figura 5 - Valores agregados à proposta}

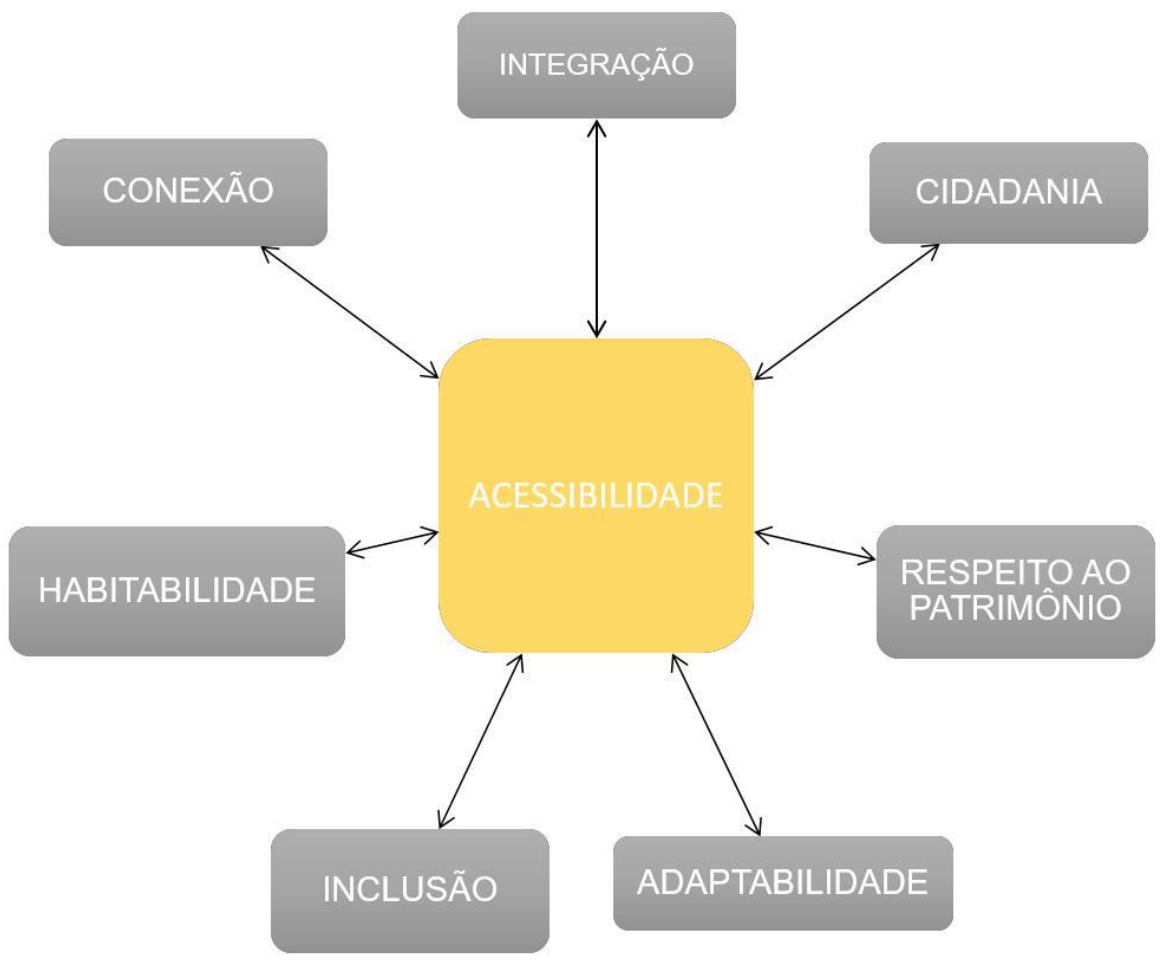

Fonte: Pesquisa de Campo.

Após o levantamento em campo e as discussões fomentadas pela análise do diagnóstico foi possível observar que o trecho do Centro Histórico de João Pessoa avaliado apresentou problemas recorrentes de inacessibilidade. Com base nesses dados foram traçadas diretrizes gerais para a viabilização de um projeto arquitetônico que contemplasse a acessibilidade no entorno imediato à HIS apontada anteriormente:

Criar uma rota acessível que conecte os lotes escolhidos para Habitação de Interesse Social aos pontos mais significativos circunvizinhos; 


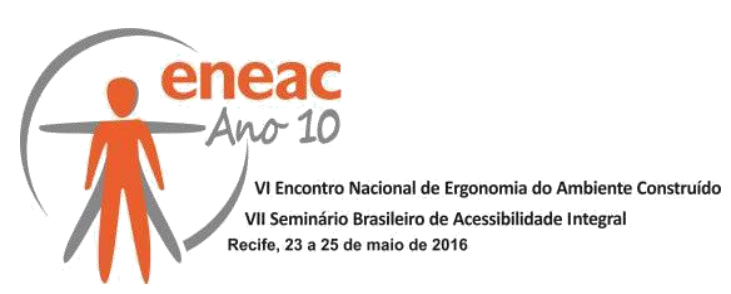

Priorizar a passagem do pedestre no passeio através da requalificação das calçadas públicas;

Interligar os principais serviços ao lote destinado para a Habitação de Interesse Social contribuindo, desta maneira, para consolidar a habitabilidade do local;

Conectar os principais corredores viários através dos abrigos de paradas de transporte coletivo público, melhorando o deslocamento dos moradores da HIS para outras partes da cidade.

A RAE (Figura 6) busca interligar prioritariamente quatro pontos: os dois imóveis cotados para HIS, a Creche Maria da Luz e um ponto de Ônibus da Rua das Trincheiras. A creche foi escolhida devido ao fato deste serviço iniciar a formação do cidadão e apoiar o processo de construção de conhecimento e habilidades por parta da criança. Está intrínseca também a possibilidade de desenvolvimentos da família (especialmente a mulher), visto que é um espaço de acolhimentos de crianças, dando condições da mãe trabalhar, ganhar um salário e estar presente no mundo do trabalho. (DIDONET, 2001)

Por fim, o ponto de ônibus, pelo fato do transporte coletivo ter papel essencial nas cidades, democratizando a mobilidade, contribuindo para minimizar congestionamentos e não exigir a necessidade da construção de vias e estacionamentos (ARAÚJO, 2011). A sua interligação permite às pessoas a expansão da mobilidade para outros locais da cidade, uma vez que possibilita, por exemplo, que o indivíduo se desloque da rota proposta para uma outra em outro ponto por meio do sistema de transporte público.

Figura 6 - Mapa dos pontos interligados pela rota.

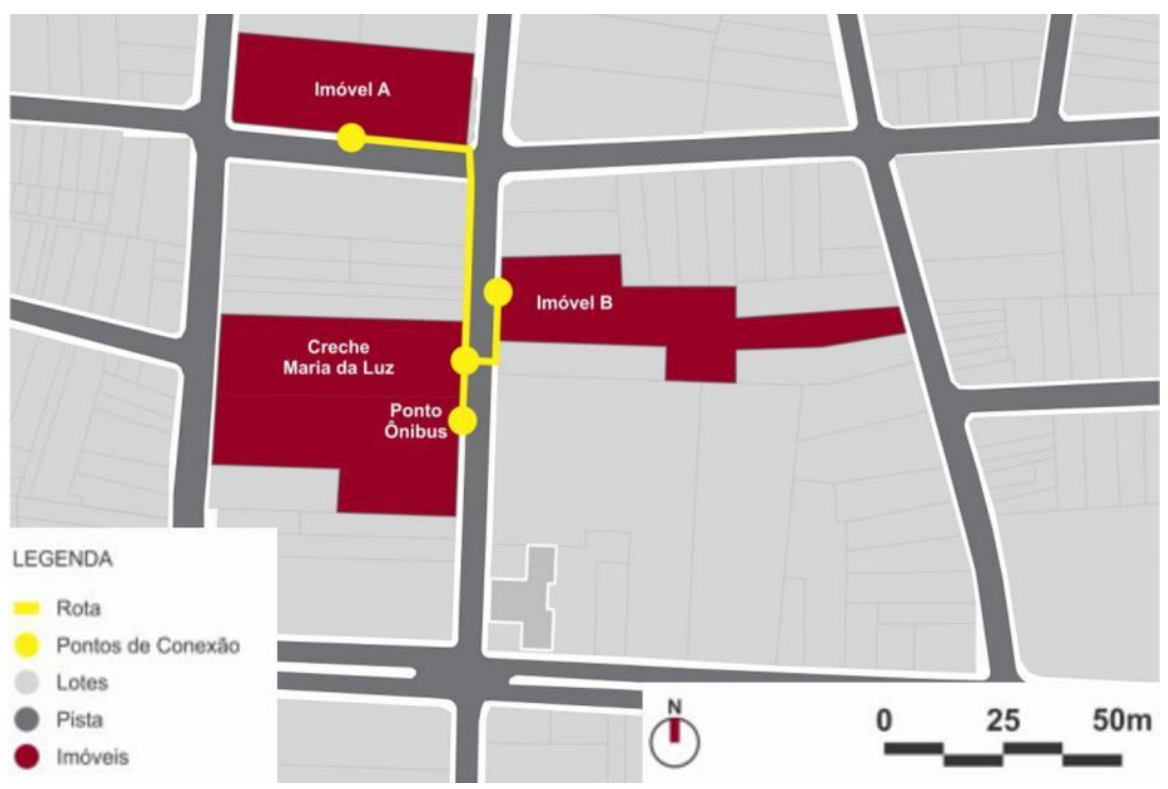

Fonte: Pesquisa de Campo

As calçadas foram divididas em três faixas de uso seguindo as recomendações da cartilha "Conheça as regras para arrumar sua calçada" (SÃO PAULO, 2012), do Código de Trânsito Brasileiro (BRASIL, 1997) e da NBR 9050/2015 (ABNT, 2015):

Faixa de serviço: Localizada entre o passeio e a pista de rolamento, abriga os equipamentos e mobiliários urbanos (postes, lixeiras, telefones públicos sinalização, canteiros de arborização urbana, entre outros). 


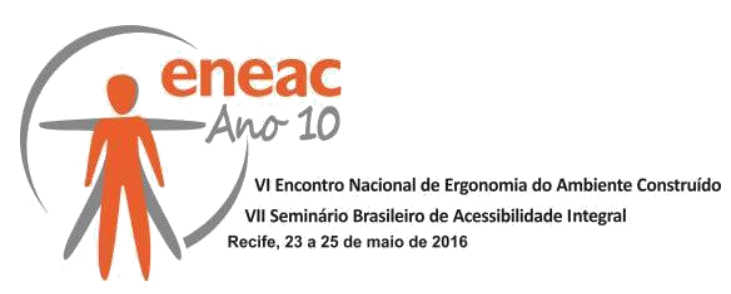

Faixa Livre: com largura mínima de 1,50m a partir do limite com a faixa de serviço, é o espaço destinado exclusivamente à circulação dos pedestres. Não pode conter interferências, como vegetação e mobiliário urbano. Deve possuir superfície regular, continua e antiderrapante.

Faixa de Acesso: sem largura mínima, localiza-se entre a faixa livre e o lote. É uma faixa de apoio e serve para amenizar o conflito entre os transeuntes que circulam pela calçada e os que se destinam aos lotes, também pode abrigar mobiliário de apoio, desde que estes não impeçam o acesso aos imóveis.

Nos trechos onde não foi possível locar as três faixas (Figura 8), prevaleceu o uso da faixa livre em detrimento das faixas de serviço e de acesso, respectivamente. Abaixo segue ilustração que mostra essa situação.

Figuras 7 e 8 - Divisão da calçada em faixas.

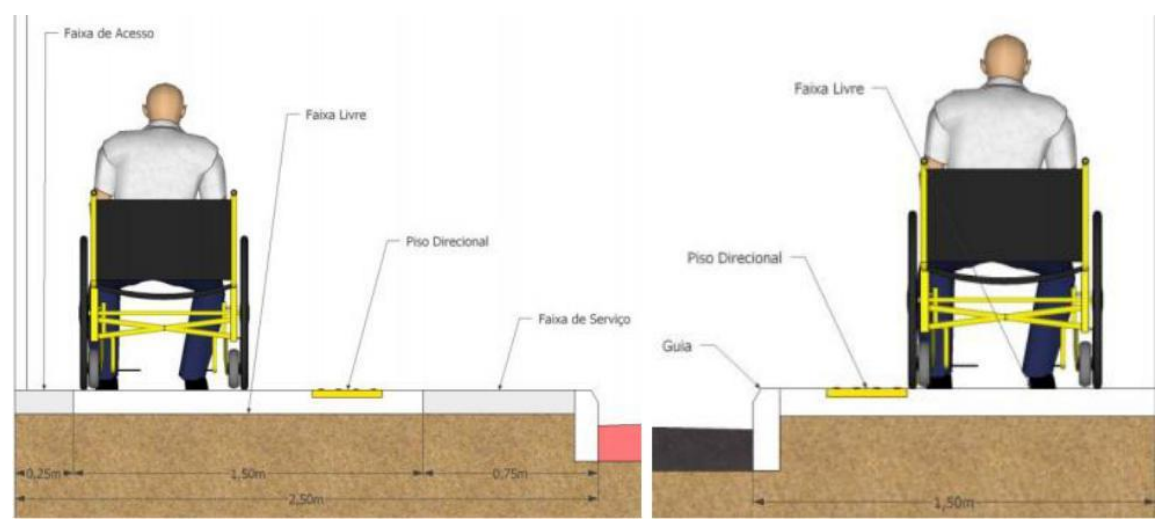

Fonte: Pesquisa de Campo

A RAE possui aproximadamente $150 \mathrm{~m}$ (Figura 9) e conta com um piso em acabamento regular, não trepidante e com inclinação transversal de $3 \%$. A travessia de pedestres é realizada por faixas elevadas. O piso tátil, por recomendações do trabalho de Costa (2014), foi pensado de forma a evitar o conflito no tráfego de pedestres, por isso está situado em um dos lados do passeio, não no eixo central.

Figura 9 - Planta esquemática da rota.

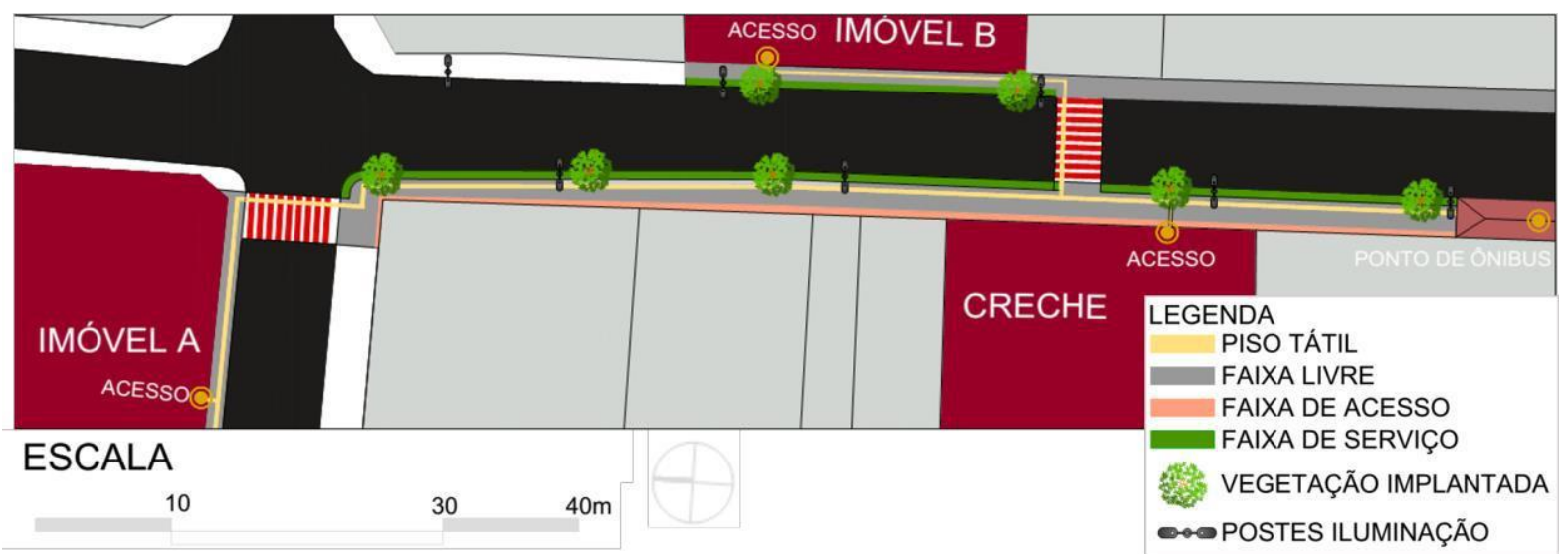

Fonte: Pesquisa de Campo 


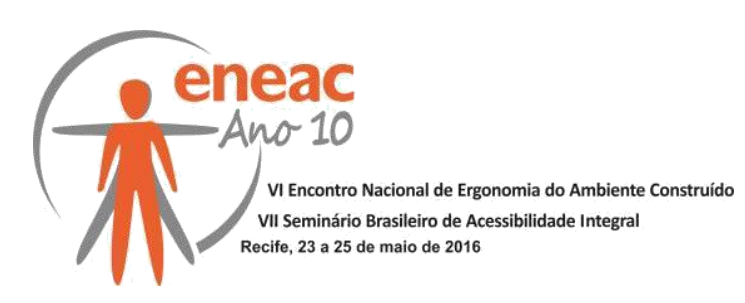

\section{CONSIDERAÇÕES FINAIS}

O Centro Histórico de João Pessoa expandiu-se e consolidou-se mantendo o espaço urbano carente de acessibilidade. A partir das visitas realizadas nessa área foi possível observar que ainda há muito o que fazer para garantir nesse, espaços democráticos e acessíveis.

O presente estudo revelou a necessidade e possibilidade de inserir acessibilidade na área, uma vez que, observou-se que cerca de $99 \%$ do espaço avaliado mostra-se passível de adaptação, enquanto que os poucos obstáculos apontados são, em maioria, superáveis com intervenções primárias.

$O$ alcance dessa pesquisa permitiu conhecer a realidade de um trecho desse Centro Histórico e suas possibilidades de projeto. A implantação de uma RAE na área, que possa integrar os lotes elencados para HIS e os serviços próximos, não somente mostrou-se possível, como também representa a possibilidade de integração e o resgate da dinâmica urbana do local.

\section{REFERÊNCIAS BIBLIOGRÁFICAS}

ÁLVAREZ, Eduardo; CAMISÃO, Verônica. Guia operacional de acessibilidade para projetos de desenvolvimento urbano - com critérios de desenho universal. Informe técnico do Banco Interamericano de Desenvolvimento. 2002. Disponível em: <http://www.iab.org.br/sites/default/files/Guia\%20BID\%20Vers\%C3\%A30\%20Portugu\%C3\%AAs.pdf>. Acesso em: 23 Ab. 2015.

ARAÚJO, Marley Rosana Melo de et al. Transporte público coletivo: discutindo acessibilidade, mobilidade e qualidade de vida. Psicologia \& Sociedade, v. 23, n. 3, p. 574-582, 201.1

ASSOCIAÇÃO BRASILEIRA DE NORMAS TÉCNICAS - ABNT. NBR 9050: Acessibilidade a edificações, mobiliário, espaços e equipamentos urbanos. Rio de Janeiro: ABNT, 2015.

BRASIL. Constituição (1988). Constituição da República Federativa do Brasil. Brasília, DF: Senado Federal: Centro Gráfico, 1988. 292p.

BRASIL. Decreto lei no 9.503, de 23 de setembro de 1997. Institui o Código de Trânsito Brasileiro. Disponível em: <http://www.planalto.gov.br/ccivil_03/LEIS/L9503Compilado.htm>. Acesso em: 19 abr. 2013.

CARVALHO, M.L.A.M.; SANTOS, V.A.; NETO, J.M.S. Habitação e desenvolvimento social no centro histórico de Salvador. In: SEMINÁRIO INTERNACIONAL URBICENTROS III, 2012. Salvador. Anais...Salvador, 2012.

CASTRO, Amaro Muniz. Centro Histórico de João Pessoa: Ações, Revitalização e Habitação. 2006. 106 f. Dissertação (Mestrado) Centro de Tecnologia. Universidade Federal da Paraíba. João Pessoa.

COSTA, Angelina; et al. Avaliando o desempenho de uma rota acessível na UFPB. In: ENCONTRO NACIONAL DE TECNOLOGIA DO AMBIENTE CONSTRUÍDO, 15., 2014, Maceió. Anais.... Maceió: Antac, 2014. p. 1 - 08

DIDONET, Vital. Educação infantil: a creche, um bom começo. Em Aberto/Instituto Nacional de Estudos e Pesquisas Educacionais, v. 18, n. 73, p. 11-28, 2001. 


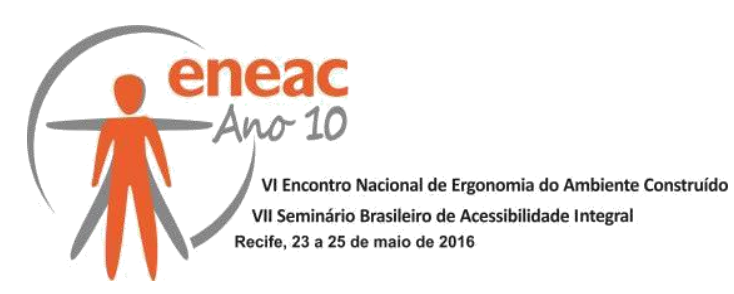

DUARTE, Cristiane Rose; COHEN, Regina. Acessibilidade como fator de construção do lugar. In: LOPES et al. (Orgs.). Desenho Universal: caminhos da acessibilidade no Brasil. São Paulo: Ed. Annablume, 2010. P. 81 - 94.

LARCHER, José Valter Monteiro. Diretrizes Visando a Melhoria de Projetos e Soluções Construtivas na Expansão de Habitações de Interesse Social. 2005. Tese de Doutorado. Universidade Federal do Paraná.

REIS, A. T. L.; LAY, M. C. D. Percepção e Análise dos Espaços: desenho universal. In: PRADO, A. R. de A.; LOPES, M. E.; ORNSTEIN, S. W. Desenho Universal: caminhos da acessibilidade no Brasil. 1ed. São Paulo: Annablume, 2010.

SÃO PAULO. Conheça as regras para arrumar sua calçada. Cartilha: Prefeitura de São Paulo, 2012. Disponível em: <http://www.prefeitura.sp.gov.br/cidade/secretarias/upload/subprefeituras/calcadas/arquivos/cartilha_draft_10.pdf>. Acesso em: 21 abr. 2013.

TUAN, Yi-Fu. Espaço e Lugar: a perspectiva da experiência. São Paulo: DIFEL, 1983. 250 p. 